\title{
HIGH ENCAPSULATION EFFICIENCY OF SODIUM ALENDRONATE IN EUDRAGIT S100/HPMC BLEND MICROPARTICLES
}

\author{
Letícia Cruz, Evelise Assumpção e Sílvia Stanisçuaski Guterres \\ Faculdade de Farmácia, Universidade Federal do Rio Grande do Sul, Av. Ipiranga, 2752, 90610-000 Porto Alegre - RS, Brasil \\ Adriana Raffin Pohlmann* \\ Instituto de Química, Universidade Federal do Rio Grande do Sul, CP 15003, 91501-970 Porto Alegre - RS, Brasil
}

Recebido em 16/5/08; aceito em 12/12/08; publicado na web em 11/5/09

\begin{abstract}
The hydrophilic drug sodium alendronate was encapsulated in blended microparticles of Eudragit ${ }^{\oplus}$ S100 and Methocel ${ }^{\oplus}$ F4M or Methoce ${ }^{\circledR}$ K100LV. Both formulations prepared by spray-drying showed spherical collapsed shape and smooth surface, encapsulation efficiencies of 85 and $82 \%$ and mean diameters of 11.7 and $8.4 \mu \mathrm{m}$, respectively. At $\mathrm{pH} 1.2$, in vitro dissolution studies showed good gastro-resistance for both formulations. At pH 6.8, the sodium alendronate release from the microparticles was delayed and was controlled by Fickian diffusion. In conclusion, the prepared microparticles showed high encapsulation efficiency of sodium alendronate presenting gastro-resistance and sustained release suitable for its oral administration.
\end{abstract}

Keywords: hydrophilic drug; sodium alendronate; microparticles.

\section{INTRODUCTION}

Sodium alendronate (Figure 1) is a bisphosphonate used in the treatment of several bone metabolism disorders including Paget's disease and osteoporosis. ${ }^{1,2}$ However, sodium alendronate oral administration is associated with adverse gastrointestinal events such as gastroesophageal inflammation and ulceration, esophageal erosions and gastrointestinal bleeding. ${ }^{3-5}$

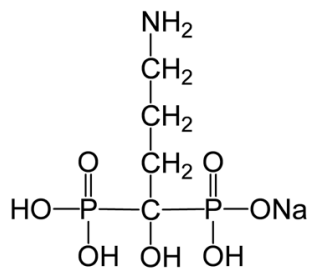

Figure 1. Chemical structure of sodium alendronate

The low oral bioavailability of sodium alendronate (less than $1 \%$ ) is attributed to its poor lipophilicity, which prevents transcellular transport across the epithelial barriers. ${ }^{2}$ Among the different strategies to circumvent the low bioavailability of drugs, the microencapsulation is one of the most important. ${ }^{6}$ However, the microencapsulation of water-soluble drugs presenting low molecular weight is a difficult task because the formulations usually showed low encapsulation efficiencies and rapid release profiles due to the affinity of the drug by the aqueous medium. ${ }^{7,8}$ Spray-drying and multiple emulsions have been widely employed to prepare polymeric microparticles for either water soluble or water insoluble drugs using hydrophilic and hydrophobic polymers. ${ }^{9-12}$

There are few reports in the literature dedicated to the microencapsulation of sodium alendronate or other bisphosphonates. The preparation of poly(D,L-lactide-co-glycolide-D-glucose) microparticles containing $30 \%$ of pamidronate was feasible using a non-aqueous solid-in-oil-in-oil (S/O/O) solvent evaporation method. ${ }^{13}$ In another

\footnotetext{
*e-mail: pohlmann@iq.ufrgs.br
}

study, clodronate-loaded poly(D,L-lactide-co-glycolide) (PLGA) microspheres prepared by water-in-oil-in-water emulsion $(\mathrm{W} / \mathrm{O} / \mathrm{W})$ solvent evaporation method showed drug contents ranging between 4 and $9 \%$. In this case, drug release has been tailored from $48 \mathrm{~h}$ up to 3 months by selecting the composition and the conditions for microparticle preparation. ${ }^{14}$

Samdancioglu et al. ${ }^{15}$ prepared sodium alendronate-loaded PLGA and chitosan microspheres by solvent evaporation using W/O/W emulsion and emulsion polymerization techniques, respectively. Sodium alendronate was $85 \%$ released in 3 days from chitosan microspheres, whereas the drug was $58 \%$ released in 5 days from PLGA microspheres. However, the formulations presented low drug loading of 7.7 and $3.3 \%$ for PLGA and chitosan microspheres, respectively. In a recent study, ${ }^{16}$ microspheres prepared by W/O/O solvent evaporation technique showed maximum alendronate loading of $10 \%$, encapsulation efficiency of $106 \%$ and drug controlled delivery over a period of 13 days.

Most of the studies mentioned above, which used PLGA as polymer and solvent evaporation as technique, were designed for bisphosphonate implantation to treat bone diseases locally. Up to now, there is no report in the literature describing the preparation of sodium alendronate-loaded microparticles by spray-drying aiming the oral delivery.

Regarding the oral administration, Eudragit ${ }^{\circledR} \mathrm{S} 100$ is a copolymer of methacrylic acid and methyl methacrylate (ratio 1:2), which dissolves at $\mathrm{pH}$ higher than 7 , therefore, providing gastric protection and enabling drug release in the intestine. ${ }^{17}$ Recently, it was demonstrated that pantoprazole-loaded microparticles prepared with Eudragit ${ }^{\circledR}$ S100 or its blend with HPMC or poli(epsilon-caprolactone) by an $\mathrm{O} / \mathrm{O}$ emulsification/solvent evaporation and spray-drying techniques were able to protect rat stomachs against ulcer formation, while the drug aqueous solution did not show this activity. ${ }^{18-21}$

Hydroxypropyl methylcellulose (HPMC) is the most used cellulose ether derivative in the formulation of hydrophilic matrices for oral controlled drug delivery systems. ${ }^{22,23}$ HPMC presents high swellability, which has a significant effect on the release kinetics of encapsulated drugs. Depending on the HPMC degree of substitution and chain length, different release profiles of encapsulated drugs can be observed. ${ }^{24,25}$ 
Taking all of this into account, the aim of this work was to encapsulate a hydrophilic drug, sodium alendronate, in microparticles by spray-drying using blends of Eudragit ${ }^{\circledast}$ S100 and Methocel ${ }^{\circledR}$ F4M (MP-F4M) or Eudragit ${ }^{\circledR}$ S100 and Methocel ${ }^{\circledR}$ K100LV (MP-K100) in order to obtain gastro-resistant and sustained release formulations. We hypothesized that Eudragit ${ }^{\circledR}$ S100 could promote the gastro-resistance and HPMC would allow the drug controlled release by Fickian diffusion. Furthermore, the different microparticle viscosities achieved using Methoce $^{\circledR}$ F4M and Methoce ${ }^{\circledR} \mathrm{K} 100$ could influence the drug release profiles. The physicochemical properties and the in vitro release characteristics of the sodium alendronate-loaded microparticles were studied by laser diffratometry, scanning electron microscopy and spectrophotometry. For the latter, an adapted methodology was validated to determine quantitatively sodium alendronate in the microparticles and during the drug release studies.

\section{EXPERIMENTAL}

\section{Materials}

Monosodium alendronate trihydrate was obtained from Henrifarma (São Paulo, Brazil). Eudragit ${ }^{\circledR}$ S100 (EUD) was supplied by Almapal (São Paulo, Brazil) and Methocel ${ }^{\circledR}$ F4M and Methocel ${ }^{\circledR}$ K100LV were supplied by Colorcon (Cotia, Brazil). o-Phthalaldehyde was obtained from Invitrogen (Carlsbad, USA) and 2-mercaptoethanol was acquired from Acros Organics (Geel, Belgium). All other chemicals and solvents were of pharmaceutical grade and used as received.

\section{Analytical procedure}

The total amount of sodium alendronate in the formulations was measured by spectrophotometric method proposed by Al Deeb and co-workers ${ }^{26}$ with some adaptations. This method is based on the ability of sodium alendronate to form an UV-absorbing derivative with o-phthaldialaldehyde (OPA). A stock solution of sodium alendronate was prepared by dissolving $100 \mathrm{mg}$ of the drug in $0.2 \mathrm{M} \mathrm{NaOH}(100$ $\mathrm{mL}$ ). The derivatizing reagent was prepared by dissolving $50 \mathrm{mg}$ of OPA with $5 \mathrm{~mL}$ of $0.05 \mathrm{M} \mathrm{NaOH}$. Then, $250 \mu \mathrm{L}$ of 2-mercaptoethanol solution was added and the volume was completed to $50 \mathrm{~mL}$ with 0.05 $\mathrm{M} \mathrm{NaOH}$. Calibration curves were prepared in the range of 10-60 $\mu \mathrm{g} . \mathrm{mL}^{-1}$ by adding aliquots of the stock sodium alendronate solution in volumetric flasks. Four milliliters of the derivatizing agent were added to each flask and the volume was completed to $50 \mathrm{~mL}$ with $0.2 \mathrm{M} \mathrm{NaOH}$. The absorbance values were measured at $333 \mathrm{~nm}$. To validate this method the following parameters were analyzed: specificity, linearity, limit of quantification, precision and accuracy. ${ }^{27}$ The linearity was evaluated by the least square regression method. Additionally, a study was performed in order to optimize the time of reaction between sodium alendronate and OPA, and to determine the time of the derivative stability. The calibration curves were analyzed $15,30,45,60$ and 90 min after derivatization.

\section{Preparation of sodium alendronate loaded-gastro-resistant microparticles}

Microparticles using a blend of EUD and Methocel ${ }^{\circledR}$ K100 (MP-K100) or a blend of EUD and Methocel ${ }^{\circledR}$ F4M (MP-F4M) were prepared by spray-drying. Firstly, the EUD $(5.0 \mathrm{~g})$ was dissolved in $0.05 \mathrm{M} \mathrm{NaOH}(500 \mathrm{~mL})$ under magnetic stirring at $50^{\circ} \mathrm{C}$. After dissolution, Methoce ${ }^{\circledR} \mathrm{K} 100$ or Methoce ${ }^{\circledR} \mathrm{F} 4 \mathrm{M}(2.5 \mathrm{~g})$ was added and the mixture was kept under mechanical stirring for $10 \mathrm{~min}$. This gel was kept at $4{ }^{\circ} \mathrm{C}$ for $48 \mathrm{~h}$ until the complete dissolution of HPMC. Sodium alendronate $(2.0 \mathrm{~g})$ was added in the solution before spray-drying (MSD 1.0, LabMaq, Brazil). The operational conditions were: feed rate of $0.40 \mathrm{~L} \mathrm{~h}^{-1}$, air flow rate of $500 \mathrm{NL} \mathrm{h}^{-1}$, atomizing air pressure of $3.7 \mathrm{Kgf}\left(\mathrm{cm}^{2}\right)^{-1}$, inlet temperature of $150{ }^{\circ} \mathrm{C}$ and nozzle diameter of $1.2 \mathrm{~mm}$. Additionally, the formulations MP-K100-placebo and MP-F4M-placebo were prepared without the drug and were used to determine the specificity and accuracy of the analytical method for sodium alendronate quantification.

\section{Determination of encapsulation efficiency and drug loading}

A portion of microparticles equivalent to $10 \mathrm{mg}$ of sodium alendronate was accurately weighed and dissolved volumetrically with $0.2 \mathrm{M} \mathrm{NaOH}$. After $60 \mathrm{~min}$, the sample was filtered (Whatman $\mathrm{n}^{\circ} 40$ ), and $10 \mathrm{~mL}$ of the filtrate were transferred to another $50 \mathrm{~mL}$ volumetric flask. Then, $4 \mathrm{~mL}$ of derivatizing reagent were added and the volume was completed with $0.2 \mathrm{M} \mathrm{NaOH}$. After $30 \mathrm{~min}$, the absorbance was measured at $333 \mathrm{~nm}$. The encapsulation efficiency of each formulation was calculated based on the theoretical and the experimental sodium alendronate concentrations, and expressed as percentage. Determinations were made in triplicate.

\section{Particle size}

The particle size and size distributions were determined by laser diffractometry (Malvern Mastersizer 2000, Malvern Instruments, UK) after dispersion of microparticles in iso-octane. The particle sizes were expressed as the mean diameter over the volume distribution $\mathrm{d}(4.3)$ and the size distributions (span) were calculated using Equation 1.

span $=\frac{[d(0.9)-d(0.1)]}{d(0.5)}$

where $\mathrm{d}(0.1), \mathrm{d}(0.5)$ and $\mathrm{d}(0.9)$ are, respectively, the particle diameters at 10,50 and $90 \%$ of the undersized particle distribution curve.

\section{Scanning electron microscopy}

The morphological examination of the microparticles was performed by scanning electron microscopy (SEM) (Jeol Scanning Microscope, JSM-5800, Tokyo, Japan). The powders were carbon and gold sputtered (Jeol Jee 4B SVG-IN, Tokyo, Japan) before the analyses (Centro de Microscopia Eletrônica-UFRGS, Porto Alegre, Brazil). ${ }^{28}$

\section{In vitro gastro-resistance}

To evaluate the enteric nature of the microparticles, the study was performed in a dissolution apparatus (Vankel VK7010, VanKel Technology, Cary, USA) at $37{ }^{\circ} \mathrm{C}$, using the basket method at a rotation speed of $100 \mathrm{rpm}$. Microparticles were poured into a vessel containing $900 \mathrm{~mL}$ of $0.1 \mathrm{M} \mathrm{HCl}(\mathrm{pH} 1.2)$. Samples were withdrawn every half-hour up to $2 \mathrm{~h}$ and analyzed spectrophotometrically using OPA as derivatizing agent. The samples $(1 \mathrm{~mL})$ were treated with OPA $(0.4 \mathrm{~mL})$ and the volume was completed volumetrically to 5 $\mathrm{mL}$ with $5 \mathrm{M} \mathrm{NaOH}$. The absorbances were analyzed at $333 \mathrm{~nm}$ after $30 \mathrm{~min}$. The study was conducted in triplicate.

\section{In vitro drug release}

In vitro profiles of sodium alendronate released from microparticles were evaluated in phosphate buffer pH 6.8 (Vankel VK7010, VanKel Technology, Cary, USA). For comparison, the dissolution of the pure drug was also determined. The samples were collected at predetermined intervals $10,15,30,45,60,90,120,150,180,240$, $300,360,420,480,540,600$ and $660 \mathrm{~min}$. The amount of sodium 
alendronate released was analyzed by the derivatization of the samples $(1 \mathrm{~mL})$ with OPA $(0.4 \mathrm{~mL})$ in a volumetric flask $(5 \mathrm{~mL})$. The volume was completed with $0.2 \mathrm{M} \mathrm{NaOH}$. After $30 \mathrm{~min}$, the absorbances were analyzed at $333 \mathrm{~nm}$. The study was conducted in triplicate.

\section{Mathematical modeling}

The mathematical fit of the release profiles was performed using the model-dependent approaches monoexponential (Equation 2) and biexponential (Equation 3).

$$
\begin{aligned}
& \frac{M_{t}}{M_{\infty}}=1-\left[e^{-k t}\right] \\
& \frac{M_{t}}{M_{\infty}}=1-\left[A \cdot e^{-\alpha \cdot t}+B \cdot e^{-\beta . t}\right]
\end{aligned}
$$

where $M_{t}$ is the amount of the drug released at time $t, M_{\infty}$ is the initial concentration of the drug, $\mathrm{k}, \alpha$ and $\beta$ are the apparent release kinetic rate constants, $\mathrm{A}$ and $\mathrm{B}$ are the fractions of the drug that contributed to the burst and sustained phases, respectively. ${ }^{29,30}$

The Korsmeyer-Peppas model ${ }^{31}$ (Equation 4) was used to explain the drug release mechanism. In this equation, $\mathrm{ft}$ is the ratio of absolute cumulative amount of the drug released at time $t$ and at infinite time, $\mathrm{k}$ is a constant incorporating structural and geometric characteristic of the carrier, and $\mathrm{n}$ is the release exponent, indicative of the mechanism of the drug release. For a drug delivery system presenting spherical geometry, $\mathrm{n}$ value of 0.43 corresponds to a Fickian diffusion of the drug, while $\mathrm{n}$ values ranging from 0.43 to 0.85 indicate that the mechanism is dependent of the drug diffusion and the swelling of the polymer (anomalous transport). Finally, $n$ values equal to or higher than 0.85 correspond to a case II transport (relaxation controlled delivery). ${ }^{32}$

$f t=\frac{M_{t}}{M_{\infty}}=k \cdot t^{n}$

In all cases the fit was carried out using the Scientist 2.0 software (Micromath, USA). The selection of the model was based on the best correlation coefficient and the best model selection criteria (MSC), both provided by the software, and the best graphic adjustment.

\section{RESULTS AND DISCUSSION}

\section{Analytical procedure}

From the analytical point of view, sodium alendronate assay is a difficult task due to the lack of chromophores absorbing photons between 200 and $800 \mathrm{~nm}$. The reactions of OPA with amino compounds in the presence of nucleophilic agents to give isoindole derivatives are used for the analytical determination of primary amines and amino acids. ${ }^{33,34}$ OPA does not interfere in the absorbance of the derivatives, eliminating the need for post-derivatization removal excess of reagent. ${ }^{26}$ In this way, this spectrophotometric method was studied to determine the stability of the OPA derivative using different times of reaction. The calibration curves presented maximum absorbance after 30 and $45 \mathrm{~min}$ of reaction (Figure 2). Even though isoindole derivative is quantified after $60 \mathrm{~min}$ of reaction by $\mathrm{Al}$ Deeb and co-workers, ${ }^{26}$ our results showed that after this period the absorbance reduced of about $20 \%$. So, in the present study the quantification of sodium alendronate was carried out after $30 \mathrm{~min}$ of the derivatization reaction.

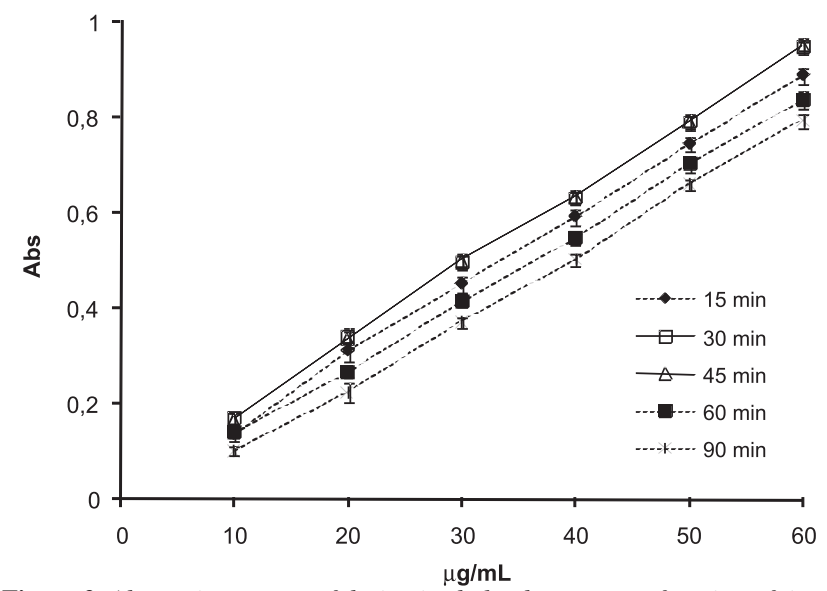

Figure 2. Absorption curves of derivatized alendronate as a function of time

The specificity was determined by analysis of the absorption spectra of a sodium alendronate solution added of OPA $(40 \mu \mathrm{g}$ $\mathrm{mL}^{-1}$ ), a solution of sodium alendronate and OPA at $\mathrm{pH} 6.8$ phosphate buffer $\left(60 \mu \mathrm{g} \mathrm{mL}^{-1}\right)$, a drug-free microparticle formulation (placebo) and a physical mixture of the drug and the placebo formulation $\left(40 \mu \mathrm{g} \mathrm{mL}^{-1}\right)$. Figure 3 shows the spectra of the drugfree microparticle (MP-K100-placebo and MP-F4M-placebo) demonstrating the absence of interfering peaks and that no reaction between OPA and the placebo microparticles occurred. Moreover, the absorbances of the sodium alendronate solution and the physical mixture of the drug and the placebo formulations were similar. The linearity was observed between 10 and $60 \mu \mathrm{g} \mathrm{mL}^{-1}(\mathrm{r}>$ $0.9996)$, inter- and intraday variability did not exceed $2.1 \%$ and the limit of quantification was $9.93 \mu \mathrm{g} \mathrm{mL}^{-1}$. Accuracy was determined for both formulations at 15,35 and $55 \mu \mathrm{g} \mathrm{mL}^{-1}$. The values were $98.9 \pm 2.0 \%, 98.6 \pm 2.1 \%$ and $99.5 \pm 1.9 \%$ for MP-F4M and 99.4 $\pm 2.7 \%, 100.3 \pm 1.6 \%$ and $98.9 \pm 1.3 \%$ for MP-K100.

\section{Preparation and characterization of microparticles}

The microparticles drug loadings were 16.2 (MP-F4M) and $15.6 \%$ (MP-K100) corresponding to high encapsulation efficiencies (Table 1$)$. The mean diameters $\left(\mathrm{d}_{4.3}\right)$ of the microparticles were 11.7 (MP-F4M) and $8.4 \mu \mathrm{m}$ (MP-K100) with span values close to 2. To verify the influence of the drug on the size distribution of the micro-

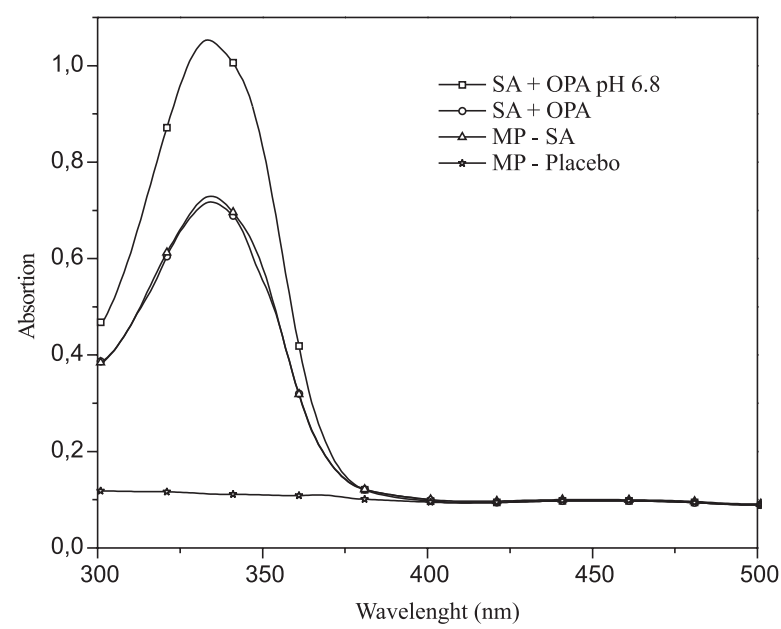

Figure 3. Absorption spectra of sodium alendronate added of OPA (SA + $O P A)$, pure sodium alendronate (SA), microparticles containing sodium alendronate (MP-SA), placebo microparticles (MP-placebo) and OPA 
Table 1. Physico-chemical characteristics of microparticles

\begin{tabular}{lccccccc}
\hline Sample & $\mathrm{EE}^{* *}(\%)$ & $\begin{array}{c}\text { Drug } \\
\text { loading }(\%)\end{array}$ & $d_{0.1}(\mu \mathrm{m})$ & $d_{0.5}(\mu \mathrm{m})$ & $d_{0.9}(\mu \mathrm{m})$ & $d_{4.3}(\mu \mathrm{m})$ & \multicolumn{3}{c}{ Particle size distribution } \\
\hline MP-F4M* & - & - & 2.5 & 8.4 & 30.1 & 12.9 & 2.3 \\
MP-F4M & $85.0 \pm 1.3$ & $16.2 \pm 3.4$ & 2.9 & 8.7 & 20.3 & 11.7 & 8.5 \\
MP-K100* & - & - & 2.4 & 7.0 & 14.9 & 1.9 \\
MP-K100 & $82.2 \pm 1.1$ & $15.6 \pm 2.1$ & 2.1 & 6.8 & 15.4 & 8.4 & 2.0 \\
\hline
\end{tabular}

*Unloaded microparticles ** Encapsulation efficiency

particles, placebo formulations were also prepared. Comparing each drug-loaded blend microparticle formulation with the corresponding placebo, similar size distributions were observed showing that this parameter was not influenced by the presence of the drug. In addition, the microparticles presented similar spherical collapsed shape and smooth surface (Figure 4), and no drug crystal was observed.
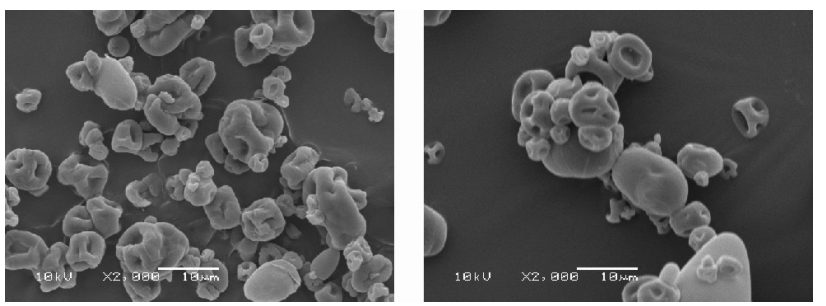

Figure 4. Photomicrographs of MP-F4M and MP-K100 formulations (bar $=10 \mu \mathrm{m})$

\section{Gastro-resistance and drug release profiles}

In order to verify the gastro-resistance, the microparticles were submitted to $0.1 \mathrm{~mol} \mathrm{~L}^{-1} \mathrm{HCl}$ (pH 1.2). Within $2 \mathrm{~h}, 12$ and $10 \%$ of the drug were released from MP-F4M and MP-K100, respectively (Figure 5).

Concerning the in vitro dissolution profiles at $\mathrm{pH} 6.8$, pure sodium alendronate dissolved $99.7 \%$ within $10 \mathrm{~min}$, while the release of the drug from the microparticles (MP-F4M and MP-K100) were, respectively, 98.1 and $97.9 \%$ in $540 \mathrm{~min}$ (Figure 6). In spite of the different viscosity and the degree of substitution of HPMC (Methoce ${ }^{\circledR}$ F4M and Methocel ${ }^{\circledR} \mathrm{K} 100 \mathrm{LV}$ ), the drug release profiles are similar to one another $(\mathrm{p}>0.05)$. The microparticles combined gastro-resistance and enterosolubility due to the use of EUD and HPMC.

The release profiles were fit to monoexponential and biexponential equations (Table 2). Considering the values of correlation coefficient and MSC, the release of sodium alendronate was better

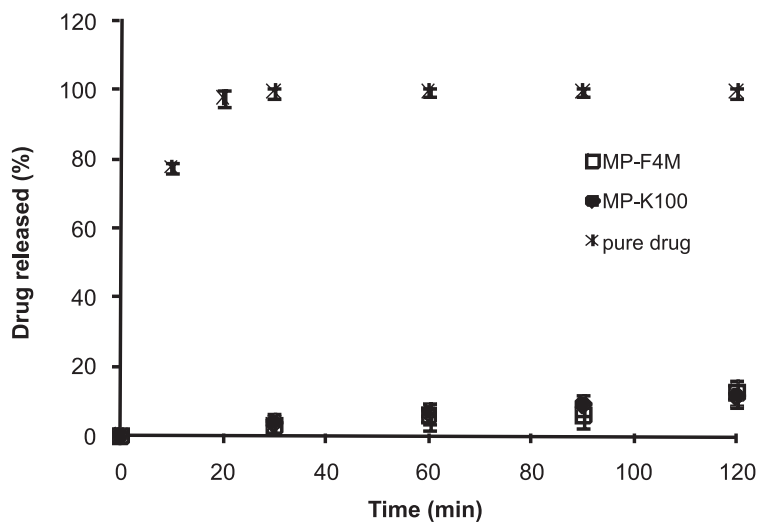

Figure 5. Dissolution profiles of MP-F4M and MP-K100 formulations in 0.1 mol.L $L^{-1} \mathrm{HCl} \mathrm{pH} 1.2$

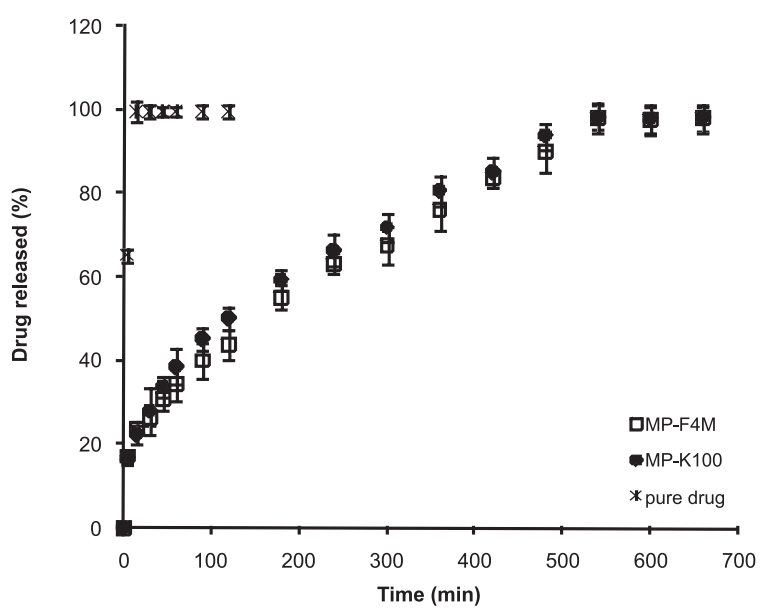

Figure 6. Dissolution profiles of pure sodium alendronate, MP-F4M and MP-K100 formulations in phosphate buffer solution $\mathrm{pH} 6.8$

Table 2. Parameters calculated by monoexponential, biexponential and power law models for MP-F4M and MP-K100

\begin{tabular}{lcc}
\hline & MP-F4M & MP-K100 \\
\hline Monoexponential & & \\
$k\left(\mathrm{~min}^{-1}\right)$ & $0.0051 \pm 0.0025$ & $0.0058 \pm 0.0009$ \\
$\mathrm{r}$ & 0.9791 & 0.9808 \\
MSC & 2.2625 & 2.3112 \\
Biexponential & & \\
$\alpha\left(\mathrm{min}^{-1}\right)$ & $0.6028 \pm 0.0010$ & $0.3355 \pm 0.0013$ \\
$\beta\left(\mathrm{min}^{-1}\right)$ & $0.0038 \pm 0.0009$ & $0.0042 \pm 0.0011$ \\
$\mathrm{a}$ & $0.173 \pm 0.002$ & $0.189 \pm 0.001$ \\
$\mathrm{~b}$ & $0.827 \pm 0.001$ & $0.811 \pm 0.002$ \\
$\mathrm{r}$ & 0.9927 & 0.9938 \\
MSC & 3.6293 & 3.7997 \\
Korsmeyer-Peppas & & \\
$\mathrm{k}$ & $0.056 \pm 0.005$ & $0.067 \pm 0.005$ \\
$\mathrm{n}$ & $0.45 \pm 0.01$ & $0.42 \pm 0.01$ \\
$\mathrm{r}$ & 0.9949 & 0.9976 \\
\hline
\end{tabular}

described by the biexponential equation for both MP-F4M and MP$\mathrm{K} 100$. In this case, the release profile is composed by a biphasic curve, each phase exponentially releasing the drug. The first phase can be attributed to the burst effect (kinetic constant $\alpha$ ) and the second phase is correlated to the sustained release (kinetic constant $\beta$ ). ${ }^{29,35}$ The half-lives of the drug released from MP-F4M were calculated for 
each burst and sustained phases, being 1 and $182 \mathrm{~min}$, respectively. For MP-K100, the values of the half-lives were 2 and $165 \mathrm{~min}$ for the burst and the sustained phases, respectively. Parameters A and B showed values around 0.18 and 0.82 , respectively (Table 2). Comparing the calculated fractions with the experimental values obtained in the gastro-resistance evaluation, the drug is 10 to $20 \%$ adsorbed on the microparticles.

\section{Sodium alendronate release mechanism}

The release data were also analyzed by the Korsmeyer-Peppas model (Equation 4). The microparticles (MP-F4M and MP-K100) showed good fit with the power law presenting correlation coefficient higher than 0.99 (Table 2). The values of $\mathrm{n}$ for both formulations indicated that the release mechanism is mainly controlled by Fickian diffusion.

\section{CONCLUSION}

The blends composed by Eudragit ${ }^{\circledR}$ S100 and Methocel ${ }^{\circledR}$ F4M or Eudragit ${ }^{\circledR}$ S100 and Methoce ${ }^{\circledR}$ K100 were able to confer both gastro-resistance and controlled release to the sodium alendronateloaded microparticles. Additionally, high encapsulation efficiencies were achieved using spray-drying technique. Considering the release experiment, in spite of the high sodium alendronate water solubility, both formulations were able to retard and sustained the drug release. Furthermore, the microparticles released the drug by Fickian diffusion in simulated intestinal fluid validating our hypothesis. However, even though the microparticles were prepared with two types of HPMC (Methoce ${ }^{\circledR}$ F4M and Methocel ${ }^{\circledR} \mathrm{K} 100$ ), the difference in the HPMC viscosity did not influence the drug release profiles.

\section{ACKNOWLEDGEMENTS}

The authors thank CNPq/Brasília/Brasil, CAPES/COFECUB, FAPERGS for financial support and research grants, as well as Dr. M. I. Ré for the laser diffractometry analyses at Laboratório de Partículas, IPT-SP.

\section{REFERENCES}

1. Francis, R. M.; Curr. Ther. Res. 1995, 56, 831.

2. Lin, J. H.; Bone 1996, 18, 75.

3. Graham, D. Y.; Malaty, H. M.; Aliment. Pharmacol. Ther. 1999, 13, 515.

4. Lanza, F. L.; Hunt, R. H.; Thomson, A. B. R.; Provenza, J. M.; Blank, M. A.; Gastroenterology 2000, 119, 631.

5. Lanza, F.; Dig. Liver Dis. 2003, 35, 67.

6. Delie, F.; Blanco-Pietro, M. J.; Molecules 2005, 10, 65.

7. Lee, J-H.; Park, T. G.; Choi, H. K.; Int. J. Pharm. 2000, 196, 75.

8. Naraharisetti, P. K.; Lew, M; D. N.; Fu, Y-C.; Lee, D-J.; Wang, C. H.; J. Controlled Release 2005, 102, 345.
9. Iwata, M.; McGinity, J. W.; Pharm. Res. 1993, 10, 1219.

10. Bittner, B.; Morlock, M.; Koll, H.; Winter, G.; Kissel, T.; Eur. J. Pharm. Biopharm. 1998, 45, 295.

11. Esposito, E.; Cervellati, F.; Menegatti, E.; Nastruzzi, C.; Cortesi, R.; Int. J. Pharm. 2002, 242, 329.

12. Chaw, C. S.; Yang, Y. Y.; Lim, I. J.; Phan, T. T.; J. Microencapsulation 2003, 20, 349.

13. Weidenauer, U.; Bodmer, D.; Kissel, T.; J. Microencapsulation 2003, $20,509$.

14. Perugini, P.; Genta, I.; Conti, B.; Modena, T.; Pavanetto, F.; AAPS PharmaSciTech 2001, 2, 1.

15. Samdancioglu, S.; Calis, S.; Sumnu, M.; Hincal, A. A.; Drug Dev. Ind. Pharm. 2006, 32, 473.

16. Nafea, E. H.; El-Massik, M. A.; El-Khordagui, L. K.; Marei, M. K.; Khalafallah, M. N.; J. Microencapsulation 2007, 24, 525.

17. Kibbe, A.; Handbook of Pharmaceutical Excipients, $3^{\text {rd }}$ ed., Pharmaceutical Press: London, 2000.

18. Raffin, R. P.; Colomé, L. M.; Pohlmann, A. R.; Guterres, S. S.; Eur. J. Pharm. Biopharm. 2006, 63, 198.

19. Raffin, R. P.; Jornada, D. S.; Ré, M. I.; Pohlmann, A. R.; Guterres, S. S.; Int. J. Pharm. 2006, 324, 10.

20. Raffin, R. P.; Colomé, L. M.; Guterres, S. S.; Pohlmann, A. R.; Pharm. Dev. Technol. 2007, 12, 463.

21. Raffin, R. P.; Colomé, L. M.; Haas, S. E.; Jornada, D. S.; Pohlmann, A. R.; Guterres, S. S.; Pharmazie 2007 62, 361.

22. Colombo, P.; Adv. Drug Deliv. Rev. 1993, 11, 37.

23. Li, C. L.; Martini, L. G.; Ford, J. L.; Roberts, M.; J. Pharm. Pharmacol. 2005, 57, 533.

24. Siepmann, J.; Peppas, N. A.; Adv. Drug Deliv. Rev. 2001, 48, 139.

25. Conti, S.; Maggi, L.; Segale, L.; Ochoa Machiste, E.; Conte, U.; Grenier, P.; Vergnault, G.; Int. J. Pharm. 2007, 333, 143.

26. Al Deeb, S. K.; Hamdan, I. I.; Al Najjar, S. M.; Talanta 2004, 64, 695.

27. ICH Harmonized Tripartite Guideline; Validation of Analytical Procedures: Methodology, IFPMA: Geneva, 2005.

28. Lionzo, M. I. Z.; Ré, M. I.; Guterres, S. S.; Pohlmann, A. R.; J. Microencapsulation 2007, 24, 175.

29. Cruz, L.; Soares, L. U.; Costa, T. D.; Mezzalira, G.; Silveira, N. P.; Guterres, S. S.; Pohlmann, A. R.; Int. J. Pharm. 2006, 313, 198.

30. Cruz, L.; Schaffazick, S. R.; Dalla Costa, T.; Soares, L. U.; Mezzalira, G.; da Silveira, N. P.; Schapoval, E. E. S.; Pohlmann, A. R.; Guterres, S. S.; J. Nanosci. Nanotechnol. 2006, 6, 3154.

31. Korsmeyer, R. W.; Gurny, R.; Doelker, E.; Buri, P.; Peppas, N. A.; Int. J. Pharm. 1983, 15, 25.

32. Peppas, N. A.; Pharm. Acta Helv. 1985, 60, 110.

33. Carlson, R. G.; Srinivasachar, K.; Givens, R. S.; Matuszewski, B. K.; J. Org. Chem. 1986, 51, 3978.

34. Beketov, V. I.; Voronina, R. D.; Filatova, D. G.; Zorov, N. B.; J. Anal. Chem. 2000, 55, 1148.

35. Poletto, F. S.; Jäger, E.; Ré, M. I.; Guterres, S. S.; Pohlmann, A. R.; Int. J. Pharm. 2007, 345, 70. 